\title{
A Critical Discourse Analysis of the Reports Issued by the International Atomic Energy Agency (IAEA) Director General on Iran's Nuclear Program during the Last Decade
}

\author{
Biook Behnam \\ Department of English, Tabriz Branch, Islamic Azad University, Tabriz, Iran \\ Behzad Mahmoudy \\ Department of English, Tabriz Branch, Islamic Azad University, Tabriz, Iran
}

\begin{abstract}
Regarding the importance of Critical Discourse Analysis (CDA) in discovering the way ideology is diffused through the prevalence of various discourses, the present paper is an attempt to illustrate how the ideological and political considerations are realized through textual features of Negation and Repetition as well as intertextual features of Argumentation and Persuasion. Reports about Iran's nuclear program provided by IAEA's Director General are examples of mediating role which such genres play to dictate the underlying contemplations of their producers. Using Fairclough three-dimensional framework for studying discourse at three levels of micro, meso and macro, it is shown how the language used in these 38 reports is not merely a vehicle of explicit transmission of knowledge but a means of implicit construction of ambiguity. An attempt has been made to demonstrate how an organization such as IAEA with a technical body through politicized linguistic elements directs the readers' impression of the IAEA reports and consequently revises and constructs their ideologies.
\end{abstract}

Index Terms - CDA, IAEA, ideology, negation, repetition, reports, politicized

\section{INTRODUCTION}

Critical discourse analysis emerging from 'critical linguistics' expanded at the University of East Anglia in the 1970s, and the terms are now used often interchangeably. The ideas of Norman Fairclough, Ruth Wodak and Teun Van Dijk have always been contributing to this area. CDA as a whole network of scholars, according to Wodak (2011), initiated in the early 1990s after that a small symposium was formed in January 1991. According to Fairclough (1989) several disciplines as humanities, social sciences and particularly critical linguistics are submitting their findings to this approach. As an interdisciplinary approach to the study of discourse, CDA views language as a form of social practice and concentrates on the ways ideological and political considerations are reproduced in spoken and written texts. Demystifying ideologies and elucidating the sources of power are the common interests characterized through the systematic investigation of semiotic data whether they are written, spoken or visual (Wodak, 2011).

According to Fairclough (1994) Critical Discourse Analysis (CDA) as one of its prevailing goals aims at revealing the ideological and political investments behind the supposed abstract linguistic representations. More recently critical genre analysis can also examine how lexical or grammatical choices may display the ideological commitments of different genre producers or may normalize the power of particular groups over other (Wodak, 2011). Since work in this area is relatively new, approaches from CDA have been a valuable contribution to this area of genre analysis. Such analyses should be based on lexical and structural devices and not the biased inclination of the analysts, as this is supposed to "beg questions about representativeness, selectivity, partiality, prejudice, and voice" (Blommaert, 2005, PP. 31-32). Although maintaining total objectivity in analysis is difficult with CDA, the researchers have made their attempts to exclude any predispositions and propensity in this study.

All texts, whether spoken or written, make their meaning against the background of other texts and things that have been said on other occasions (Lemke, 1992). Text may more or less implicitly or explicitly cite other texts, they may refer to other texts, or they may allude to the past, or future, texts. We, thus, make sense of every word, every utterance, or act against the background of (some) other words, utterance, acts of similar kind (Lemke, 1995). All text are, therefore, in an intertextual relationship (Paultridge, 2006).

According to Wodak and Meyer (2009) a broad range of linguistic categories are not necessarily included in any single analysis; a researcher might come to this conclusion that just a few linguistic devices are essential to CDA studies. For example Behnam and Khodadost (2010) demonstrated how the lexical features of repetition and synonyms as well as the structural and thematic features of passivization, nominalization and predicted theme were utilized by the 
discourse producers to mediate between their own underlying ideology and the target readers understanding of the events of September 11. 2001. Moreover, Using the 5 sets of categories of inclusion/exclusion, activation/passivization, association/dissociation, individualization/ assimilation, and personalization/impersonalization, Rashidi and Rasti (2012) explored the morpho-syntactic modes through which social actors implicated in Iran's nuclear activities discourse are represented in news reports of 4 Western quality papers all dealing, one way or another, with the issue of imposing or tightening sanctions on Iran.

In another study, Behnam and Moshtaghi Zenous (2008) did a contrastive critical analysis of Iranian and British newspaper reports on the Iran Nuclear Power program. In their study they investigated how the Iranian and British press represents this program to their readers following different socio-political patterns. It was made explicit that transitivitybased foregrounding and biased transitivity use have a particularly powerful effect on one's perception of the authors' purposes and relevant contexts.

Iran's nuclear program has been a controversial issue for more than a decade since 2003 when the International Atomic Energy Agency (IAEA) first reported that Iran had not declared sensitive enrichment and reprocessing activities. After that, the IAEA's Director General publicly reported about allegations related to Iran's previously undeclared nuclear activities. Launching an investigation, the IAEA's General Director deduced in November 2003 that Iran has neglected to meet its obligation according to NPT safeguards agreement in a systematic way and reported those activities to the IAEA with no evidence of its connections to a nuclear weapons program. Since 6 June 2003 the Director General of IAEA has distributed 38 reports regarding Iran's nuclear program with a lot of commonalities and differences.

Iran has regularly refused to stop its enrichment program, claiming that the program is unavoidable for its energy security. While Most of the IAEA members confirm the peaceful entity of Iran's nuclear program other countries as western side accuse Iran of unpeacefull atomic activities. Due to these opposite viewpoints hot discussions between the two sides have been made in different meetings. None of these meetings has come to an appropriate conclusion yet.

After an IAEA report in November 2011, the IAEA Board of Governors regretted that before 2003 Iran had likely endeavored to undertake research and experiments aiming at developing nuclear weapons capabilities. This cast doubts on the possible military dimension of Iran's nuclear program which paved the way for creating an atmosphere of threat and insecurity in the Middle East so that western countries could sell more military weapons and could implement more nuclear projects in the region. Moreover, such an allegation permitted Security Council to impose severe sanctions against Iran creating a lot of scientific, economical and social problems

Perhaps the structure and strategies of argumentation in political texts are the most pervasive, where a political dispute may evolve due to both explicit and implicit assumptions, the different steps of argumentation as well as the conclusions drawn. Through a textual and an intertextual analysis of 38 reports released by IAEA Director General regarding Iran nuclear program, the researchers are trying to uncover the political and ideological considerations tacitly realized by means of textual features of repetition and negation as well as intertextual discursive strategies of persuasion and argumentation. This kind of analysis seeks to answer the following questions;

1. How are textual features of Repetition and Negation used to convey the political ideologies latent in the IAEA reports?

2. How are the report producers trying to implement the intended, political contemplation by means of intertextual strategies of persuasion and argumentation?

\section{METHODOLOGY}

Fairclough (1989 cited in Wikipedia) developed a three-dimensional guideline for studying discourse. His aim was to map three distinct forms of analysis onto one another: analysis of (spoken or written) language texts, analysis of discourse practice (processes of text production, distribution and consumption) and analysis of discursive events as examples of sociocultural practice. Specifically, he combined micro, meso and macro-level interpretations. At the micro-level, the analyst is concerned with the text's syntax, metaphoric structure and certain rhetorical devices. The meso-level comprised studying the text's production and consumption, concentrating on how power relations are enacted. At the macro-level, the analyst considers intertextual relationships, trying to understand the broad, societal currents that are influencing the text being studied. As such the method used here involves disclosing the political and ideological considerations through examining how the linguistic means and specific context dependent linguistic realizations are manifested at micro, meso and macro levels.

\section{Micro level}

Fairclough (1995a) claims texts can use lexical choices to indicate level of authority and co-membership with the audience. Authors will often seek to influence us through claims to having power over us. They will use specific, official sounding terms that help to convey authority. With regard to this level, the 38 reports of IAEA director General are analyzed to account for the procedures through which the lexical features of Negation and Repetition were used to carry the intentions embedded in linguistic representations. Hence the number of negative as well as repeated words and sentences by means of required software is counted. Also the reports producers' metaphorical structure of the texts is analyzed to account for the intended illusions and delusions used to dictate authority.

2. Meso level 
According to Fairclough (1992) CDA is an attempt to make up for the lack of development of the nature of the link between language, power and ideology and accounts for the process of revealing those political and ideological investments. Also Van Dijk (1993) thinks that CDA is an attempt to reveal the social relations of power which exist in texts both explicitly and implicitly. A critical approach to discourse is trying to discover the links between the text (micro level) and the masked power structures in society (macro sociocultural practice level) by means of discursive practices based on which the text was produced (meso level) (Thompson, 2002). In other words, a text, an account of something that is taking place in a larger social context abundant with a complex set of power relations, is interpreted and induced by readers or listeners depending on the rules, norms, and mental models of the society they live in. By comparing and analyzing the language used in these 38 reports an attempt is made to unveil such discursive strategies of argumentation and persuasion some of which are explicitly articulated and others implicitly.

3. Macro level

Research in CDA has been mainly concerned with the persuasive influence of power, a conception of power associated with Gramsci (1971), whose concept of hegemony describes the ways through which dominant groups in society succeed in persuading subordinate groups to accept the former's own moral, political and cultural values and institutions. Through ethnographic information and analyzing intertextual relationship of the reports it is discussed how the concept of hegemony is practiced throughout these reports.

\section{DATA ANALYSIS AND DiscUSSION}

The data for the present study comprises 38 reports by IAEA Director General from 2003 to 2012 downloaded from IAEA Official Internet Site. These reports were varied from 5 pages to 30 pages depending on Iran's nuclear program. All the reports were analyzed carefully in terms of cohesive and coherent devices which at micro, meso and macro level influenced the readers' conceptions of the texts.

\section{A. Data Analysis and Discussion at Micro Level}

At micro level the reports were analyzed in terms of negation and repetition. Nearly all the negated words, suffixes and prefixes as not, no, nor, un, never, any, none, rarely, n't etc, were searched in the texts carefully so that the most frequent ones be found. From among the many negated words used the four 'not', 'no', 'nor', and prefix 'un' were the most frequent which were repeated as follow; 'not' 505 times, 'no' 91 times, 'no' 37 times and 'un' 184 times. As figure 1 shows a comparison has been made between the use of negation concerning specifically Iran's nuclear program and the negative words used in the whole reports.1576 occurrences of negation with regard to the four negated words and the aforementioned prefix were found from among which 833 (\%52.8) were devoted to Iran's nuclear program.

Some of the phrases in which the negation or the negated words are frequently used are as follows: not previously declared, not been declared to the agency, not available to the agency, were not consistent with, not technically plausible, no specific information, etc.

Also there are some negative sentences as follows based on which the reports' producers have tried to convey their ideologies;

- The information provided by Iran has not been adequate.

- Iran has not provided specific information regarding its nuclear program.

- Iranian authorities indicated that they were not yet ready to discuss ....

Contrary to the relevant resolutions of the board of Governors and the Security Council, Iran is not implementing its additional protocol.

Through the deliberate use of 833 negation or negated words in the reports, the reports producers want to put emphasis on this claim that Iran is inattentive to IAEA rules and regulations. So this paves the way for putting severe sanctions against Iran, the point they have successfully achieved recently.

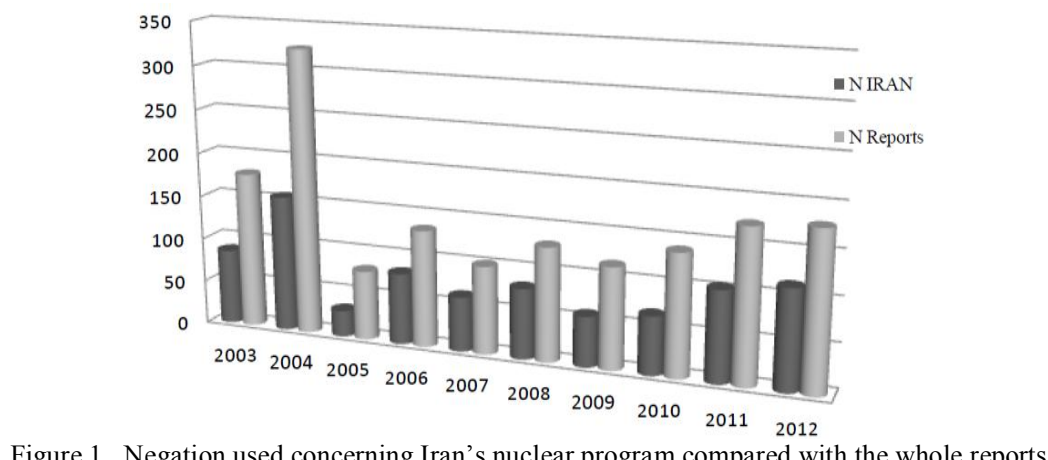

Repetition is a lexical cohesive device which refers to words that are repeated in a text. The deliberate repetition of some items in a text may be due to this fact that the writer wants to put special emphasis on something so as to create a special effect in readers' mind. 
In the IAEA reports, the producers have intently tried to absorb the readers' attention to the point that Iran's nuclear program is mysterious and that Iran does not provide precise information regarding its nuclear program. In other words by repeating some special items as 'undeclared, uncertainties, inconsistencies, unresolved, concerned, possible military dimension, contamination' they have made an attempt to depict a picture which shows that the nature of Iran's nuclear program is not peaceful.

1. The words undeclared was repeated 105 times, uncertainties 20 times, inconsistencies 9 times and unresolved 10 times to indicate the world that Iran's nuclear program in essence is ambiguous and obscure.

2. The word concerned was used 22 times in the reports to create an atmosphere of anxiety and solicitude in the region.

3. The word military 186 times and the phrase possible military dimension 98 times were repeated in the IAEA reports to indicate that Iran's nuclear program is not peaceful. The exaggeration in the foregrounding of this phrase implies that the reports producers are trying to draw the readers' attention away from the peaceful nature of Iran's nuclear program and toward its possible military side.

4. The word contamination was repeated 195 times to illude the readers that Iran nuclear program is not peaceful.

\section{B. Data Analysis and Discussion at Meso Level}

Knowing that political forms of texts have political functions and implications, an attempt has been made to explore how through discursive devices of argumentation and persuasion the IAEA reports producers are trying to change the readers' ideology and beliefs regarding Iran's nuclear program. The sentences used throughout the 38 reports reveal how the writers put special terminologies in sentences to depict a picture that Iran's nuclear program is insecure and uncertain.

- We were not sure ...

- Agency does not have any concrete information....,

- Iran has not provided specific information...,

- Iranian Authorities do not provide sufficient insurance...,

- Iran did not inform the agency...,

- Iran provided information not provided earlier...,

- The agency cannot verify the accuracy of estimate...,

- The agency is not in a position to verify...,

- No specific information was provided...,

None of these activities involving nuclear material had been reported to the agency.

The information provided by Iran has not been adequate.

- Contrary to the board resolutions ... and despite the intensified dialogues between the Agency and Iran ..., it has not been possible to agree on the structured approach.

- Iran has failed to report the receipt and use of uranium metal.

The above sentences used in the reports creates an atmosphere of doubt and mistrust for the world public and the members of the Treaty on the non-Proliferation of Nuclear weapons (NPT) that Iran is disloyal to the international rules and regulations.

Moreover the report producers have tried to persuade the readers to follow the possible military dimension of Iran's nuclear program. The following sentences have been repeated throughout the reports to convey such an idea.

- The agency ... is waiting for Iran to address the other topic which could have a military nuclear dimension,

- Iranian authorities indicated that they were not yet ready to discuss... .

The use of the word 'could' shows that the report producers without having any concrete information are trying to occupy the readers mind with this idea that Iran's nuclear program has a military dimension and that they should wait for future new information regarding this issue.

Moreover, the report producers constantly (more than 700 times) refers the readers back to the issues presented in one of reports in 2003 about "a large number of conversion, fabrication and irradiation activities involving nuclear material, including the separation of a small amount of plutonium" although in that report the agency confessed that "to date there is no evidence that the previously undeclared nuclear material and activities referred to above were related to a nuclear weapons program".

Going through the reports reveals that from one hand the IAEA deserves an authoritative role for itself using words such as 'must', 'should', 'is required' and from the other hand the Director General makes use of 'is not able' or 'unable' to show that the Agency is not in a position to judge about Iran's nuclear program. These contradictory roles cast doubt about the right and fair position that the Agency could play in solving the so-called problem of Iran's nuclear program.

- The Director General is unable to report any progress on the clarification of outstanding issues.

- The Agency will not be able to resolve concerns about issues regarding the Iranian nuclear program.

In the reports provided by IAEA from 2010 to 2012 only one paragraph in each report with the title of 'Facilities Declared under Iran's Safeguards Agreement' has been used to show the peaceful and secure nature of Iran's nuclear programme, while 23 paragraphs in 2008, 16 paragraphs in 2009, 11 paragraphs in 2010, 17 paragraphs in 2011, 
and 22 paragraphs in 2012 have been used under the title of 'Possible Military Dimensions' to depict a picture in the readers' mind that Iran's nuclear program is unsafe and insecure.

\section{Data Analysis at Macro Level}

According to Van Dijk (1997) predicates of the macrostructure of political discourse tend to be future-oriented. Given the role of discourse in the political process, we may typically expect references to or threats about future developments, announcements or promises about future actions and so on. Quiet typical for much political discourse is the fact that references to the past are ambiguous, those to the present negative and those to the future positive ( Van Dijk, 1997, p. 17). This is what which is actually seen in the 38 reports provided by IAEA. In these reports ambiguous, long and repeated references has been made to the past, a lot of negation and negative words has been produced regarding the current state of Iran's nuclear program and trivial positive hopes has been made with regard to future actions Iran's may undertake.

The research in CDA has been mainly concerned with the persuasive influence of power, a conception of power associated with Gramsci (1971), whose concept of hegemony describes the ways through which dominant groups in society succeed in persuading subordinate groups to accept the formers' own moral, political and cultural values and institutions (Machin \& Mayer, 2012). In democratic societies one of which is the place where these reports were released, power needs to be seen as legitimate by people in order to be accepted, and this process of legitimation is generally accepted through language and other communicative systems. The IAEA, on the other hand (unlike the UN), is not supposed to be a politicized body. It was established to be a purely technical body, tasked with independently verifying state compliance with agreements related to fissile materials accounting. A close analysis of the 38 reports reveals that how a technical organization such as IAEA enacts the notions of power and hegemony by means of politicized texts.

The reports' analysis at meso level revealed instances of how the writers persuaded the readers in accepting the possible unsecure nature of Iran's nuclear program. At macro level an attempt is made to show how the report producers in the many reports practice the hegemony by means of persuading Iran to stop its nuclear program or at least to accept the obligations made by the IAEA.

According to Fairclough (1995) often texts can use lexical choices to indicate level of authority and co-membership with the audience. Authors will often seek to influence us through claims to having power over us. They will use specific, official sounding terms that help to convey authority. A close analysis of the IAEA's reports reveals 69 occurrences of the word "urge", 89 occurrences of the word 'essential', 23 times occurrences of the word 'urgent', all of which are related to persuading Iran to apply the IAEA's obligations and regulations. Some of the instances are the followings.

- The Director General continues to urge Iran to take steps towards the full implementation of its safeguards.

- It is essential that Iran also provide without further delay substantive answers to the Agency's detailed questions.

- The board of governor has adopted two resolutions addressing the urgent need to resolve outstanding issues regarding the Iranian nuclear program.

These and all other instances are examples of authoritative role the IAEA plays in persuading Iran to accept the obligations and requirements assigned by IAEA.

\section{CONCLUSION}

The IAEA purposeful tracking record in dedicating so much judgmental concern to Iran over the past 10 years, and not to other non-nuclear-weapon countries who have continuously participated in exactly the same production of knowledge and capabilities, by means of precisely similar processes, has been convincing for both Iran and the other members of the Non-Aligned Movement (including the vast majority of countries in the world) that the IAEA has thereby injured its independence and objectivity as an agency, which is pursuing technical monitoring and verification of other countries atomic capabilities. Instead, it is believable that it has become a highly politicized means of the foreign policy goals of the United States and other Western countries. Furthermore, the largest portion of the 38 reports is historical which refers to the years leading up to 2003. Its interpretation is considerably dependent on whether you are a glass half-full or half-empty sort of person. While the IAEA is claiming as trying to develop atomic energy investments among its members, it has confirmed beyond credible doubt through publicized and politicized reports that there is a centralized, tremendously established nuclear program in Iran, which is deliberately for military purposes. These points, altogether, establish an insecure and unsafe atmosphere in the world which is intended by the IAEA report producers and world powers.

\section{REFERENCES}

[1] Behnam, B. \& Khodadost, M. R. (2010). A critical discourse analysis of September 11, 2001 in America and Syrian print media discourse. Journal of Applied Linguistics, Iran. 3, pp 23- 43.

[2] Behnam, B. \& Moshtaghi Zenous, R. (2008). A contrastive critical analysis of Iranian and British newspaper reports on the Iran Nuclear Power program. Journal of Systemic Functional Linguistics in Use. OWPLC, 29, pp, 199-218. 
[3] Blommaert, J. (2005). Discourse. Cambridge: CPU.

[4] Fairclough, N. (1989). Language and Power. London: Longman.

[5] Fairclough, N. (1992). Discourse and Social Change. Cambridge: Polity.

[6] Fairclough, N. (1994). Conversationalisation of Public Discourse and the Authority of the Consumer. In N. Abercrombie, R. Keat \& Whiteley (eds), The Authority of the Consumer. London: Routledge.

[7] Fairclough, N. (1995). Critical Discourse http://www.Ling.lances.ac.uk/staff/norman/critdiscanalysis.doc (accessed 2/3/2013).

[8] Gramsci, A. (1971). Selections from the Prisoners Notebooks. New York: International Publisher. Retrieved from London: ElecBook.

[9] Lemke, J.L. (1992). Interpersonal Meaning in Discourse: Value Orientations. In M. Davies \& L. Ravelli (Eds), Advences in systematic Linguistics: Recent Theory and Practice (pp. 82-104). London: Pinter.

[10] Lemke, J. L. (1995). Textual Politics; Discourse and Social Dynamics, Bristol, DA: Taylor \& Francis, p. 23.

[11] Machin, D. \& Mayr, A. (2012). How to Do Critical Discourse Analysis: A Multimodal Introduction. Retrieved from http://www.books.google.com (accessed 12/5/2013).

[12] Paltridge, B. (2006). Discourse Analysis. London: MPG Books LTD.

[13] Rashidi, N. \& Rasti, A. (2012). Doing (in) justice to Iran's Nuke activities. A critical discourse analysis of news reports of four western quality newspapers. American Journal of Linguistics, 1(1), pp. 1-9.

[14] Van Dijk, T. A. (1993). Principles of Critical Discourse Analysis; Discourse \& Society. London: Routledge.

[15] Van Dijk, T. A. (1997). What is political discourse analysis?, in Belgian Journal of Linguistics. Retrieved From http://www.discourses.org/OldArticles/What is Political Discourse Analysis.pdf (accessed 5/4/2013).

[16] Wodak, R. \& Meyer, M. (2009). Methods of Critical Discourse Analysis. London: SAGE publication. Retrieved from http://www. books.google.com (accessed 20/4/2013).

[17] Wodak, R. (2011). Critical Linguistics and Critical Discourse Analysis. In J. Zienkowski and J. Ostman and J. Verschueren, Discursive Pragmatics: a Handbook of Pragmatics Highlights (pp. 50-70). Amsterdam: John Benjamin Publishing Company.

[18] https://en.m.wikipedia.org/wiki/Critical_discourse_analysis.

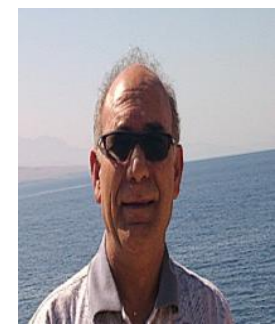

Biook Behnam is an Associate Professor in Applied Linguistics in Islamic Azad University, Tabriz Branch, Iran. His current research interests cover Discourse Analysis, ELT and Translation Studies. He has been involved in a wide range of projects in the area of Applied Linguistics and Discourse Analysis as a project director, consultant and Researcher. He has widely presented papers to national and international conferences in North America, Australia, Europe, China, India and South East Asia.

Dr. Behnam Relevant publications include Discourse of Advertising: A comparative study (2006), with H. Piadeh, A Critical Study of Selected Political Elites in English, with L. Moghatadi and a sociolinguistic study of SMS Exchanges of Iranian Festive/Mourning Occasions, with M. R. Khodadost.

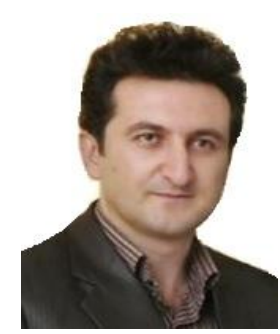

Behzad Mahmoudy is a Ph.D. candidate of TEFL in Islamic Azad University, Tabriz Branch, Iran. His research interests include Applied Linguistics, Discourse Analysis and ELT. He has been practicing his career as an English instructor in some Iranian colleges and university for 21 years. He has published a paper in ELT Voices in India and has presented papers in international conferences as a co-author.

Mr Mahmoudy has been the chancellor of Islamic Azad University, Gillan Gharb Branch, Iran, for more than four years. Meanwhile, he works as an English teacher in the Ministry of Education in Iran. 